This series aims to stimulate critical perspectives and fresh interpretive frameworks for scholarship on the history of the imposing global presence of the United States. Its primary concerns include the deployment and contestation of power, the construction and deconstruction of cultural and political borders, the fluid meanings of intercultural encounters, and the complex interplay between the global and the local. American Encounters seeks to strengthen dialogue and collaboration between historians of U.S. international relations and area studies specialists.

The series encourages scholarship based on multiarchival historical research. At the same time, it supports a recognition of the representational character of all stories about the past and promotes critical inquiry into issues of subjectivity and narrative. In the process, American Encounters strives to understand the context in which meanings related to nations, cultures, and political economy are continually produced, challenged, and reshaped. 
The Unpredictability 
MEMORIES OF

THE ASIA-PACIFIC WAR IN

U.S.-EAST ASIAN RELATIONS

\section{of the Past}

edited by Marc Gallicchio

DUKE UNIVERSTT PRESS DURHAM \& LONDON 2007 
(C) 2007 Duke University Press

All rights reserved

Printed in the United States of America on acid-

free paper $\infty$

Designed by C. H. Westmoreland

Typeset in Adobe Garamond with Goudy Old

Style display by Keystone Typesetting, Inc.

Library of Congress Cataloging-in-Publication

Data appear on the last printed page of

this book. 
TO HOSOYA CHIHIRO AND AKIRA IRIYE

With admiration and appreciation for their many contributions to scholarly exchange across the Pacific 
